Article

\title{
Analysis of dust flux and sand collection efficiency of wind erosion near surface based on field observations
}

\author{
Liu Xinchun ${ }^{1}$, Kang Yongde ${ }^{2 *}$, Chen Hongna ${ }^{3}$, Lu Hui ${ }^{4}$
}

\begin{abstract}
1.Institute of Desert Meteorology, CMA, Taklimakan Desert Meteorology Field Experiment Station of CMA, Xinjiang Laboratory of Tree Ring Ecology, Key Laboratory of Tree-ring Physical and Chemical Research of China Meteorological Administration, Urumqi 830002, China; liuxch@idm.cn;

2.State Key Laboratory of Eco-hydraulics in Northwest Arid Region of China, School of Water Resources and Hydroelectric Engineering, Xi'an University of Technology, Xi'an 710048, China; kyd0115@yeah.net 3.Department, Urumqi Environmental Monitoring Center, Urumqi 830001, China; liux-inchun2001@163.com 4.Key Laboratory of Ecology of Rare and Endangered Species and Environmental Protection (Guangxi Normal University), Ministry of Education, Guilin 541004, China; College of Environment and Resources, Guangxi Normal University, Guilin 541004, China
\end{abstract}

\begin{abstract}
Predicting the sand-dust horizontal flux of near-surface is a key issue for estimating the aeolian sand transport. In this paper, we designed an automatic high precision sand collector. Based on the measure data of aeolian transport, a piezoelectric saltation sensor (H11-Sensit) and a $10 \mathrm{~m}$ high meteorological tower. the sampling efficiency of auto sand sampler and horizontal dust flux of near surface were analyzed based on observed data. The results were as follows: sand collector skip turnover increased with the increase of the intensity of dust weather frequency increases, flip frequency per minute increased from 0.2794 times to 1.3041 times, change is obvious; With the strength of the weather, time to flip the average sediment is shrinking. Sandstorm weather, skip to flip a volume of $3.7160 \mathrm{~g}$, grade I flying sand weather flip a volume of $4.0275 \mathrm{~g}$, the amount of class II flying sand weather turns over a 5. 0035g.The horizontal dust flux of different dust events that calculated with the equation $\mathrm{Q}=256 \mathrm{M}$; the maximum of one dust event was about $190.335 \mathrm{~kg}$, and the minimum was $1.2 \mathrm{~kg}$. Overall, the sand transportation rate increased with wind speed. However the changes of sand transportation rate did not quite fit in with wind speed during some dust events, and in this case the corresponding surface temperature was significantly higher. The experimental data obtained can provide theoretical basis for regional sand control and enacting effective engineering measures.
\end{abstract}

Keywords: Soil erosion; Wind Erosion; Sand collection efficiency; Dust horizontal flux;

\section{Introduction}

At present, land degradation in drylands is recognized as one of the 21st century's major dust emission issues [1]. Soil and wind erosion is an important of geological and climatic phenomenon that occurs over a long period of time in the arid and semi-arid regions, where the ground surface lacks a continuous vegetation cover [2]. Both wind erosion and dust storm cause suspension of soil particles which has undergone subsequent deposition. Human activities include over-grazing, over-cropping, deforestation and so on, having a profound impact on soil and vegetation [3], resulting in increased frequency and intensity of wind erosion and dust storms in many parts of the world as well as adverse effects on soil resources, crop productivity, human health, and climate [4,5]. In some country, the annual average PM2.5 and PM10 mass concentrations high [6]. the major emission sources of PM are the degradation of soil and the mismanagement of lands [6].

A lot of studies have been carried out on the dust horizontal flux. such as Europe and outside (China, Canada, Australia, and United States), especially in the arid and msemiarid regions. On Earth, this occurs mainly in deserts, on beaches, and in other sparsely 
vegetated areas, such as dry lake beds. [7,8,9,10,11]. The lift-off velocity of different sized particles obeys different distribution functions. The mean particle velocity at different height also de-pends on the momentum exchange and particle concentration. The size distribution of sand particles in air is also important to better understand sand dust transport. Because of the difficulty of measurement, integrating samplers have historically been the most common method for measuring the flux of sand dust in field and laboratory investigations $[12,13,14]$. Several different types of measurement techniques for sand movement have been de-veloped and used in the past $[15,16,17,18,19]$ measured using sand control device $[20,21,22,23,24,25,26,27]$. Advantages of sand control device is retaining a sample for further analysis, ruggedness, omnidirectionality (points into the wind by a vane), and ability to collect sediment at multiple heights to obtain vertical integrals of transport (as opposed to single-height measurements). Initial designs were improved by increasing the efficiency through taking account of the aerodynamics associated with blocking a portion of the flow [13]. Additional improvements were made by increasing the temporal resolution through automatic weighing systems $[27,28]$ to retroactively apply a temporal signature to the mass flux of sand dust [29]. However, the spatial and temporal resolution of a mass-collecting sand dust trap remains insufficient for capturing most small-scale aeolian processes. In addition, because sand traps obstruct the aerodynamic to varying degrees, the efficiency of sampling sand dust is variable with height and wind conditions [30] but is generally around $80 \%$ [31].

The aim of this study is to understanding the sand dust transport and sampling efficiency more fully, Thus, our research group designed an automatic, long-period, and high-frequency sand sampler, was to reveal the characteristics of mass flux, mass concentration, horizontal velocity, and impact number of particles of using the field experiments with meteorological data and Sensit wind erosion sensors. thus, enhancing the understanding of the characteristics and rules of dust activities in the area.at the same time, the results from this paper can provide the input data for theoretical analysis and numerical model validation.

\section{Materials and methods}

\subsection{Study site}

The study area is the western station for wind drift sand flow observation in Tazhong (833' E, 38 $58^{\circ} \mathrm{N}$ ) in the hinterland of the Taklimakan Desert (Fig.1). which is typical temperate continental climate, with high temperature in the dry summer, rare precipitation, rich sand resources, and scarce vegetation. It has the average annual temperature of $13.6^{\circ} \mathrm{C}$, extreme maximum temperature of $46.0^{\circ} \mathrm{C}$, extreme minimum temperature of $25.0^{\circ} \mathrm{C}$, average annual precipitation of only about $25.9 \mathrm{~mm}$, average annual evaporation capacity of up to $3812.3 \mathrm{~mm}$, with frequent blowing sand and sand storm, annual winds of sand $(6.0 \mathrm{~m} / \mathrm{s}$, measured at $11.4 \mathrm{~m}$ above the ground) of more than 500 times, average wind speed of $2.5 \mathrm{~m} / \mathrm{s}$, maximum instantaneous wind speed of $20.0 \mathrm{~m} / \mathrm{s}$, and blown-sand activity index of about 8000 . The main wind directions are the ENE, EN, and NNE. The frequency of sandstorm and blowing sand is high in March-August. The regional sandstorm in this area features long duration and poor visibility. Previous studies showed that $91 \%$ of the sand grains at $5 \mathrm{~cm}$ height were in the range of $63 \sim 250 \mu \mathrm{m}$, with most in the range of $125 \sim 250 \mu \mathrm{m}[32,33]$. 


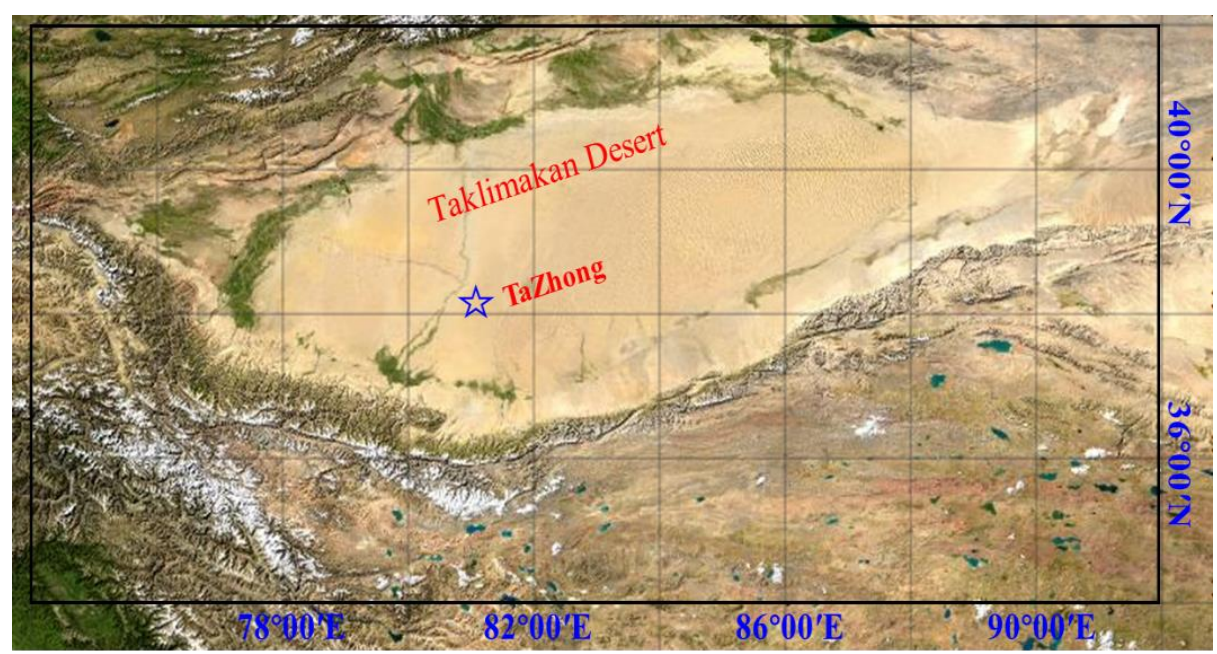

Fig. 1. A map of the study area showing the location of the experimental Tazhong site in the Taklimakan Desert of Xinjiang Province, China

\subsection{Methods}

The core structures of the sand sampler (Fig. 2) were the dust collection system and dust measurement system. The dust collection system was installed above the device enclosure (1 6 in Fig. 2), which was mainly composed of the empennage, the first air leakage network, the second air leakage network, sand intake, hollow shaft, and bearing dust proof seat. The static measurement system was in the device enclosure, which was mainly composed of the small-range high-precision dust weighting system and the large-scale dust weighting system. The small-range high-precision dust weighting system consisted of automatic sand release device and small-scale high-precision weighing sensor. The small-scale high-precision weighting sensor was mounted on the inner wall of the device enclosure, and the automatic sand release tipping bucket related to the small-scale highprecision weighting sensor. The automatic sand release device consisted of a small-capacity container (tipping bucket) and the container support shaft (Fig. 3). The small-capacity container and the container support shaft related to the flexible rod, which could rotate around the support shaft. The large-scale dust weighting system consisted of large-capacity container and the large-scale weighting sensor. The large-capacity container was mounted on the second platform. One end of the large-scale weighting sensor was fixed under the second platform and the other end was fixed on the inner wall of the device enclosure. Conveniently, the large-capacity container was designed as an inverted truncated cone-shaped container, which could help concentrate the center of the gravity of the collected objects to the sensing part of the weighting sensor. 


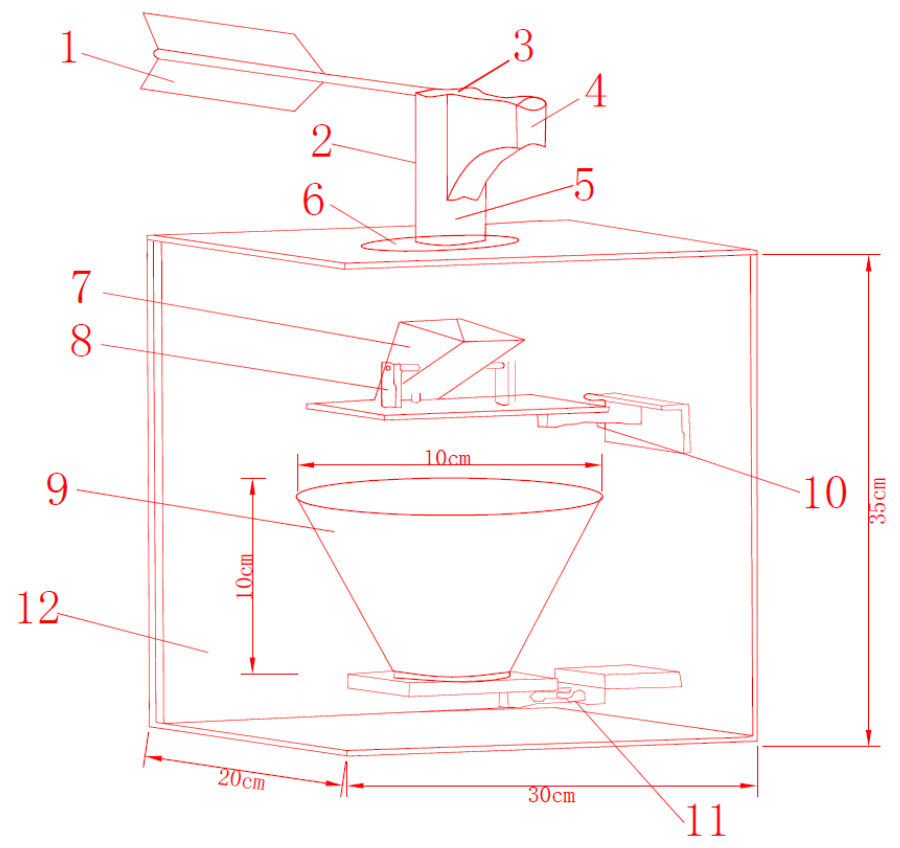

Fig. 2. Structure diagram of fully automated high-precision sand collector (1. Empennage; 2 . The first air leakage network; 3 . The second air leakage network; 4 . The mouth of into the sand; 5 . Hollow shaft; 6 . Bearing dust proof seat; 7. Small capacity container; 8. Container support shaft; 9. Large capacity container; 10 . Small range high-precision weighing sensor; 11 . Large scale weighing sensor; 12. Equipment shell).

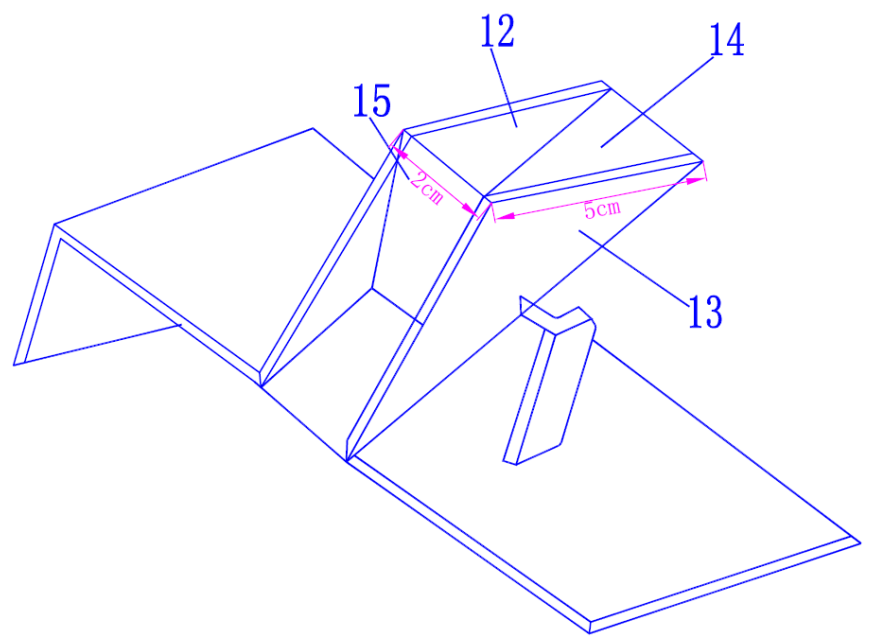

Fig. 3. Structure diagram of small capacity container (12. The first triangular plate; 13 . The second triangular plate; 14 . The first rectangular plate; 15 . The second rectangular plate).

In order to improve the measurement accuracy and range of the sand sampler, graded weighting was adopted. The range of the first-grade weighting container was $0 \sim 300 \mathrm{~g}$ with accuracy of $20 \mathrm{mg}$, and the range of the second-grade weighting container was $0 \sim 10 \mathrm{~kg}$. Sampling was carried out for twelve months. Automatic observation was realized. Aspect sensor was used to monitor the sand amount in each direction. Data acquisition system had high storage capacity (2 GB) and high frequency ( $\geq 1 \mathrm{~Hz}$ ), which could dynamically and comprehensively record the process and dynamic variation of dust emission by wind erosion in real time and weigh the collected dust in high precision and large range. During the test, the empennage could keep the sand intake consistent with the wind direction according to the wind force in the wind direction. At this point, the surface sands entered the hollow shaft through the sand intake. Sand-carrying gas 
flow could be discharged from the first air leakage network and the second air leakage network. Sands then automatically sank to the small-capacity container via gravity and the sand weighting sensor began to sense (accuracy: $20 \mathrm{mg}$ ). Finally, the weight data were uploaded to the data acquisition system. Then, the aspect sensor uploads the aspect data of the sand intake to the data acquisition system, to obtain the instantaneous sand amount in the corresponding direction. If the collected sands were over $240 \mathrm{~g}$, the tipping bucket rotated automatically to pour the sands into the large-capacity container for weighing (weight range: $0 \sim 10 \mathrm{~kg}$ ). Not only the total sand amount in the whole process was recorded, but also the data measured by the small-capacity sensor were calibrated, realizing long-term automatic monitoring, and reducing the manual workload. The data acquisition system was connected to the GPRS/CDMA communication module and power supply system and the GPRS/CDMA communication module was wirelessly connected with the computer, with which real-time online observation could be achieved off-site or onsite. The observation frequency was up to $10 \mathrm{~Hz}$. All the data in the experiment, including wind speed, wind direction, sand transport aspect, instantaneous aspect sand flux, profile sand flux, and cumulative total sand flux and were all uploaded to the data acquisition system. Through the wireless transmission network, the backstage could carry out the real-time remote automatic monitoring of the data.

The 15 dust events in July-August in 2010 were studied. The blowing sand and sandstorm were frequent in this area, which facilitated the collection of experimental data. The automatic sand sampler developed by [33] (Fig. $2 \sim 3$ ) was used, with the sand intake of 5 $\mathrm{cm} \times 2 \mathrm{~cm}$ and the collection frequency of 1s. H11-B wind erosion sensor (Sensit, US) (Fig.4) was used to record the number of sand particles impacting on sensor every second. The sensor probe was installed $5 \mathrm{~cm}$ above the ground. The sand sampler was mounted on a horizontal sand surface with the straight-line distance of $50 \mathrm{~m}$ away from the wind erosion sensor to ensure that the sand sampler empennage could rotate normally on windy days. The sand intake height of the sand sampler was the same with the height of the sensor probe. The average particle size of sands was $63 \sim 250 \mu \mathrm{m}$. The national standard test sieve was used for statistics. The sands with the particle size of greater than $74 \mu \mathrm{m}$ accounted for $75.57 \%$ and those with the particle size of greater than $50 \mu \mathrm{m}$ accounted for $97.65 \%$. The average of the two was $86.61 \%$. The actual sand collection multiplied by $86.61 \%$ was the effective weight corresponding to the number of sand particles impacting sensor. After the experiment, SigmaPlot12.5software was used for data processing and plotting.

Yang studies showed that the number of sands particles impinging sensor $(N)$ and the dust horizontal flux $(F)$ had the linear relationship, with the correlation equation as follows [34,35]:

$$
F=0.0512 N
$$

At the same time, the sand collection of BSNE sand sampler at $5 \mathrm{~cm}$ above the ground $(y)$ and the number of sand particles impacting sensor $(x)$ also had the linear relationship, with the correlation equation as follows:

$$
Y=0.0002 x
$$

Equations (1) and (2) were combined to obtain the following equation:

$$
F=256 M
$$

where, $\mathrm{M}$ is the sand collection within $5 \mathrm{~cm}$ above the ground, $\mathrm{kg}$; $\mathrm{N}$ is the number of sand particles impacting sensor, $\times 10^{3} ; \mathrm{F}$ is the horizontal flux of dust passing through the $5 \mathrm{~cm} \times 2 \mathrm{~cm}$ wide section, $\mathrm{kg}$. In the experiment, the number of sand particles impacting sensor and the sand collection also had the linear relationship, with the correlation of Equation (2). Therefore, the dust horizontal flux in this paper could be calculated with Equation (3). Sand collection efficiency was the ratio of the sand collection by the sand sampler to the actual transported sands. The correlation coefficient of the two was the average sand collection efficiency. 


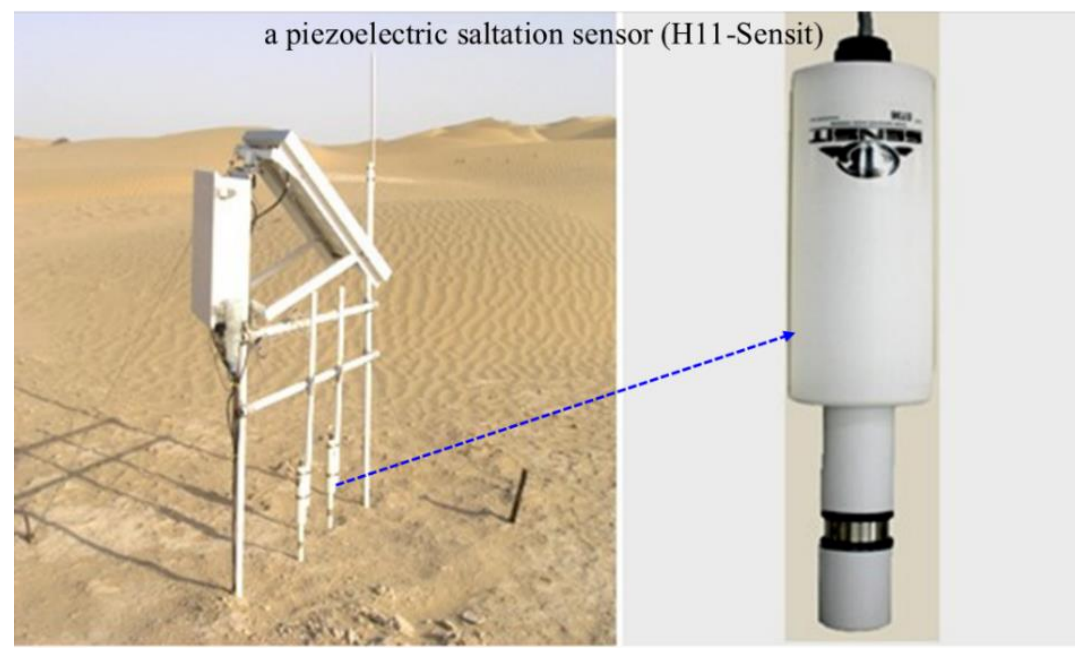

Fig. 4. Wind erosion sensor (H11-Sensit)

\section{Results and analysis}

\subsection{Sand collection and number of sand particles impacting sensor}

As shown in Table 1, in order to test the measurement performance of the automatic sand sampler, 15 typical weather events from July to August in 2010 were selected to carry out power function, exponential function, logarithmic function, linear function fitting analysis of the measured sand collection and the number of sand particles impacting the H11-sensit wind erosion sensor. Among them, the fitting degrees of the linear function fitting were obviously higher than those of the power function for 10times, and the average was also higher than that of the power function. The linear regression analysis showed that the average coefficient of determination $\mathrm{R}^{2}$ was 0.6053 . The best fitting result implied the large number of sand particles impacting the sensor and great sand collection. The result reflected that the automatic sand sampler had good sand collection capabilities in the field environment, which could well capture the movement information of the sand particles on the surface.

As for the energy, the energy gained by the impacted particles during wind-blown sand movement was extremely complex, and especially in the field, the impacted particles generally acquired mechanical energy and horizontal kinetic energy in the airflow. According to the conservation of energy theorem, the energy of the moved particles reduced in the airflow was approximately equal to the energy lost in the impacting and the total energy of impacted particles per second at a certain height could be monitored. In different periods of the 15 dust events, different wind drift sand flows were observed as influenced by the wind speed and sand source supply condition, which resulted in different fitting functions for the number of sand particles impacting sensor and sand collection in different periods in the same area. Therefore, two or more functions should be combined for the study of the relationship between the number of sand particles impacting sensor and sand collection, thereby obtaining reliable and accurate experimental results.

Table 1. Fitting analysis of saltation particle numbers and sand collection quantity.

\begin{tabular}{ccccc}
\hline Observation time & \multicolumn{4}{c}{ Determine the coefficientR } \\
\cline { 2 - 5 } & $\begin{array}{c}\text { Exponential } \\
\text { function }\end{array}$ & $\begin{array}{c}\text { Logarithmic } \\
\text { function }\end{array}$ & $\begin{array}{c}\text { Power } \\
\text { function }\end{array}$ & $\begin{array}{c}\text { Linear } \\
\text { function }\end{array}$ \\
\hline July 19(8:35-21:25) & 0.4465 & 0.6180 & 0.6900 & 0.6030 \\
July 20(19:35-21:25) & 0.3298 & 0.1755 & 0.2601 & 0.2753 \\
July 21(20:20-22day5:25) & 0.3176 & 0.3385 & 0.4452 & 0.5955 \\
July 29(22:15-30 day 2:15) & 0.4442 & 0.2937 & 0.5541 & 0.6996 \\
July 31(13:10-8.1 day 7:10) & 0.3385 & 0.2499 & 0.3458 & 0.4870 \\
August 1(21:40-23:25) & 0.6276 & 0.6787 & 0.7492 & 0.8239 \\
August 4(11:35-21:15) & 0.4360 & 0.3142 & 0.4329 & 0.7150
\end{tabular}




\begin{tabular}{ccccc} 
August 5(10:20-20:25) & 0.3227 & 0.3763 & 0.5285 & 0.7819 \\
August 7(9:30-21:55) & 0.2559 & 0.2371 & 0.2551 & 0.3788 \\
August 8(10:35-20:25) & 0.2838 & 0.4828 & 0.554 & 0.4420 \\
August 9(13:15-18:05) & 0.6037 & 0.3133 & 0.4434 & 0.8405 \\
August 13(10:30-21:25) & 0.3346 & 0.2744 & 0.3157 & 0.6281 \\
August 14(10:00-21:15) & 0.4281 & 0.3139 & 0.6445 & 0.4713 \\
August 18(10:50-20:50) & 0.4136 & 0.2095 & 0.6815 & 0.5843 \\
August 0(13:40-19:55) & 0.5423 & 0.2874 & 0.5612 & 0.7531 \\
\hline Average value & 0.4083 & 0.3442 & 0.4974 & 0.6053 \\
\hline
\end{tabular}

\subsection{Sand collector tipping-bucket efficiency analysis}

The number of sand particles impacting sensor from the 15 dust events in and the theoretical value of sand collection in Table 2 were fitted and the result showed the good linear relationship between the number of sand particles impacting sensor in the dust event and the sand collection. The coefficient of determination $\mathrm{R}^{2}$ was 0.5914 (Fig.5). Therefore, the theoretical value of sand collection in each dust event could be calculated according to the fitted linear equation. The calculated results are shown in Table 2. Statistical result showed that the theoretical value of sand collection was smaller than the observed value. The reason was that only when the correlation coefficient was 1 for the linear fitting of number of sand particles impacting sensor and sand collection, the data points could be distributed in the straight line although they were effective. The field test and wind tunnel test were different, so the correlation coefficient was not 1 and it was inevitable that the theoretical value of sand collection was smaller than the observed value.

Table 2 Saltation particle numbers observations and theoretical value of sand collection quantity

\begin{tabular}{lccc}
\hline Observation time & $\begin{array}{c}\text { Impact number } \\
\text { of particles }\end{array}$ & $\begin{array}{c}\text { Observed value } \\
\text { of sediment/g }\end{array}$ & $\begin{array}{c}\text { Theoretical value } \\
\text { of sediment quantity/g }\end{array}$ \\
\hline July $19(8: 35-21: 25)$ & 2936905 & 743.4966 & 587.3810 \\
July 20 (19:35-21:25) & 3407661 & 154.126 & 681.5322 \\
July 21 (20:20-22 day 5:25) & 920676 & 170.5492 & 184.1352 \\
July 29 (22:15-30 day 2:15) & 147786 & 34.6005 & 29.5572 \\
July 31 (13:10-1 day 7:10) & 1050073 & 179.586 & 210.0146 \\
August 1 (21:40-23:25) & 19772 & 4.5764 & 3.9544 \\
August 4 (11:35-21:15) & 195696 & 26.6128 & 39.1392 \\
August 5 (10:20-20:25) & 116005 & 12.3933 & 23.201 \\
August 7 (9:30-21: 55) & 231534 & 43.2746 & 46.3068 \\
August $8(10: 35-20: 25)$ & 1048891 & 118.5805 & 209.7782 \\
August 9 (13:15-18:05) & 1380718 & 354.3815 & 276.1436 \\
August 13 (10:30-21:25) & 210702 & 14.2759 & 42.1404 \\
August 14 (10:00-21:15) & 390274 & 25.0633 & 78.0548 \\
August 18 (10:50-20:50) & 293093 & 15.7758 & 58.6186 \\
August 20 (13:40-19:55) & 349610 & 4.5021 & 69.922 \\
\hline
\end{tabular}




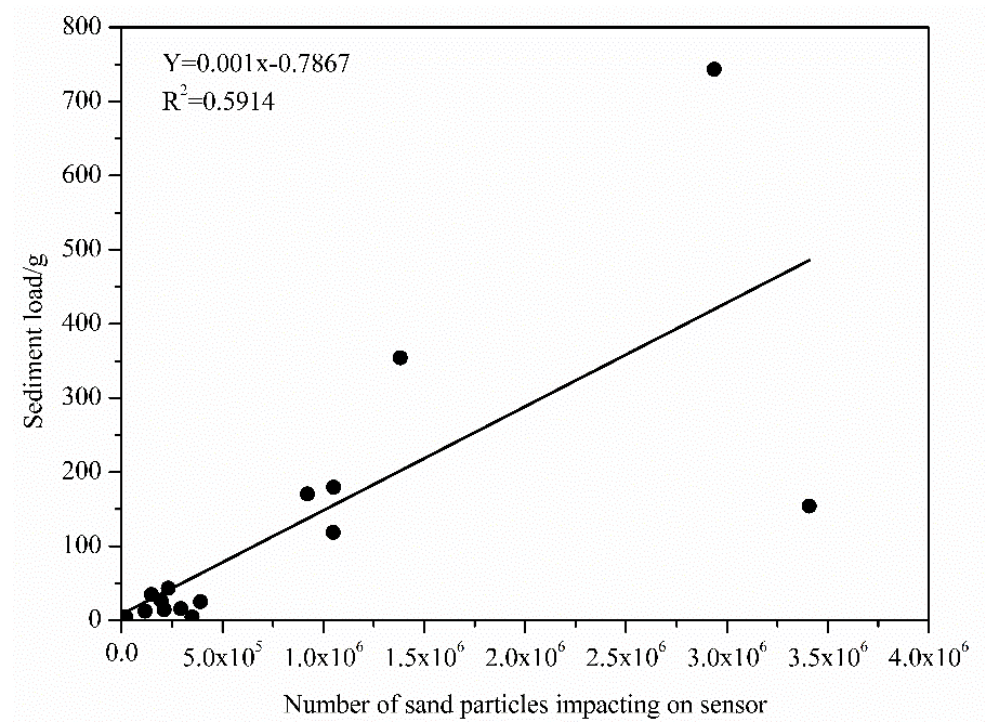

Fig. 5. Change of sand collection quantity with saltation particle numbers.

As shown in Fig. 6, the theoretical and observed sand collection were fitted and analyzed and the two had linear relationship, with the coefficient of determination $\mathrm{R}^{2}$ of only0.396 3, indicating the great error between the observed value and the theoretical value. The reason was that the theoretical value was calculated based on the actual sand collection and number of sand particles impacting sensor. In addition, the field environment was complex, which resulted in the error of the data acquisition system in the transmission process and finally reducing the accuracy. Shao found that the active sand sampler had higher sand collection efficiency than the passive sand sampler in the wind tunnel experiment and found the sand collection efficiency increased with the increase of grain size [20]. Dong found that the sand collection efficiency of the active sand sampler was $105 \%$ with the error of $\pm 5 \%$ [33]. The sand collection efficiency of the passive Leach sand sampler was $85 \%$ and the collection efficiency for the sands with the particle size of smaller than $10 \mu \mathrm{m}$ was $70 \%$. Fryrear's BSNE sand sampler had $90 \% \pm 5 \%$ collection efficiency for the eolian sands and $40 \%$ collection efficiency for sands with the particle size of smaller than $10 \mu \mathrm{m}$. Goossens et al. Other researchers found that the same sand sampler had higher efficiency for collecting eolian sands than for collecting dust $[19,20,34]$. The larger the size of the collected particles is, the higher the collection efficiency of the sand sampler is. Therefore, even for the same type of sand samplers, the sand collection efficiency was different due to different test methods. An experiment showed that the BSNE sand sampler had the sand collection efficiency of 100\%-120\% [35], while Shao concluded that the BSNE sand sampler had the sand collection efficiency of 90\% [20]. Although it was impossible to calculate the sand collection efficiency of each dust event directly based on the observed sand collection and the theoretical value of the sand collection, the average sand collection efficiency could be calculated according to the correlation coefficient between the two, i.e., the average sand collection efficiency of the sand sampler at the height of $5 \mathrm{~cm}$ was $94.3 \%$. Therefore, the method of testing the sand sampler itself is a problem worth studying. 


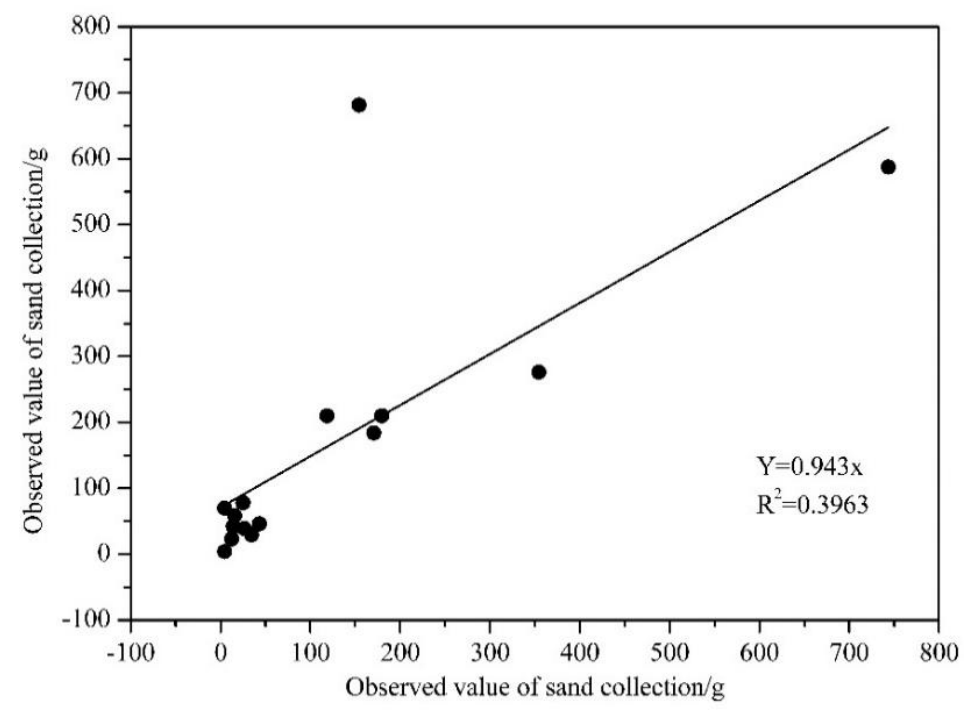

Fig. 6. Relationship between theoretical value and observed value of sediment.

\subsection{Dust horizontal flux calculation}

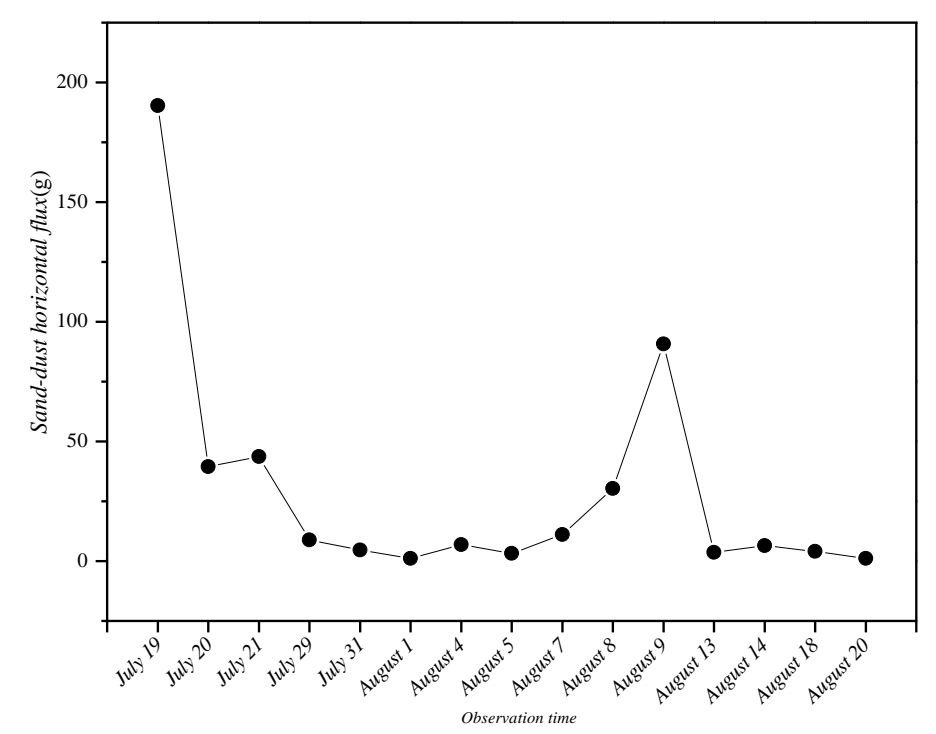

Fig. 7. Results of sand-dust horizontal flux.

The dust horizontal flux was calculated with Equation (3). The results are shown in: the dust event was defined according to Ground Meteorological Observations. The blowing sand event was defined as the phenomenon that the wind blew up sands and dusts on the ground to make the air quite turbid, with the horizontal visibility of $1 \mathrm{~km}<v<10$ $\mathrm{km}$. The sandstorm had the horizontal visibility of $<1 \mathrm{~km}$. The variation of particle size and wind speed would affect the distribution of dust horizontal flux. When the sand particle size is large, the transition height is also high, and the corresponding sand collection flux is large. It can be seen from Fig. 7 that during the 15 dust events, the maximum dust horizontal flux was $190.335 \mathrm{~kg}$, which was achieved in sandstorm. The rest events were all blowing sand events, with the minimum value of about $1.2 \mathrm{~kg}$. This observation experiment was conducted at the same sampling site, with continuous sampling time, so the impact of particle size was not taken into consideration. Only the impact of wind speed was considered. Unfortunately, more useful information was lost after the wind speeds were averaged. Therefore, the transport of most dust materials happened in the surface layer and they landed on the earth's surface by short-distance transportation. Even in sandstorm, only a small amount of dust was transported higher. For the calculation of 
dust horizontal flux, its functional relationship with height could be established with the integral, and the relationship between the sand collection within the height of $5 \mathrm{~cm}$ by the sand sampler and the dust horizontal flux could be used. Specifically, the sand collection within $5 \mathrm{~cm}$ height was weighted to calculate the dust horizontal flux. Equation (3) in this paper simplified the calculation method and reduced the computational effort.

\subsection{Sand transportation rate and wind speed}

Fig. 8 shows the relationship between sand transportation rate and wind speed under different dusty weather conditions. In general, the rate of sand-dust transport increased with the increase of wind speed, but the change trends of wind speed and sand-dust transport rate in some weather processes were inconsistent. For example, for blowing sand event (i) and blowing sand event (j), blowing sand event $(\mathrm{g})$ and blowing sand event (A), blowing sand (e) and strong sandstorm and sandstorm in fig 5, although the wind speed was small, the variation of the sand transportation rate was large. The soil temperature of $0 \mathrm{~cm}$ in corresponding time showed that the soil temperature was rapidly increased with the increase of solar radiation intensity. In the surface layer, the strong temperature-decreasing layer structure was formed in the surface layer and the thermal turbulence became stronger and stronger, resulting in enhanced heat transfer and unusually active sand saltation. When the wind speed was small but the sand transportation rate was relatively large, the corresponding soil temperature of $0 \mathrm{~cm}$ was large. This showed that the increased soil temperature of $0 \mathrm{~cm}$ could promote the saltation of sands. This was consistent with the research result of that the "synchronization of wind and temperature" was in favor of the co-occurrence of wind and saltation [35]. The specific relationship of the sand transportation rate with wind speed and temperature needs to be further studied.

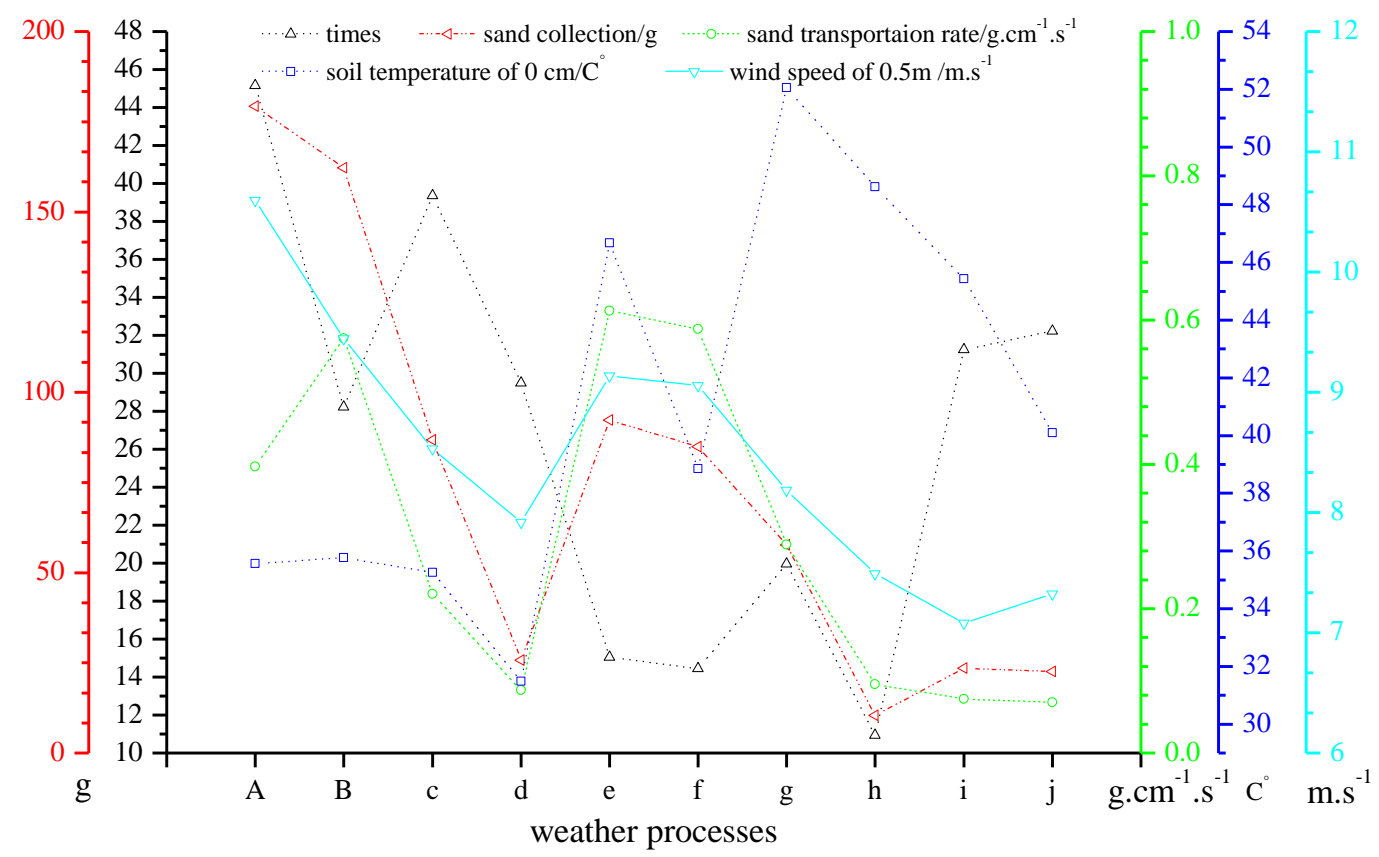

Fig. 8. Sediment of different dust events.

\section{Discussion}

There are many factors affecting the horizontal flux of sand dust. In addition to the differences in the collection instruments, there are many other factors in terms of physical mechanisms, which are summarized as the following points.

Movement of sand dust in response to wind is the most important feature of aeolian sediment transport. The wind accelerated Impact particles and eject more particles when impacting the surface, lead to the horizontal dust flux in the initial stages were increase 
$[36,37]$. However, this rapid increase in the impact particle concentration produces a corresponding increase in the drag of dust particles on the fluid, there by retarding the wind speed. This in turn reduces the speed of horizontal dust flux particles, such that a steady state is reached when the speed of impact particles is reduced to a value at which there is a single particle leaving the soil surface for each particle impacting it [38]. beause of the finite response time of dust flux particle speeds to the wind speed, the horizontal dust flux can 'overshoot' the eventual steady state mass flux [39,40,41].

Jasper F Kok study found that the modification of the wind profile through momentum transfer to impact particles [10]. on the one hand, it is the retardation of the wind profile through drag by saltating particles that ultimately limits the number of particles that can be saltating under given conditions. on the other hand, the drag by saltating particles re-duces the horizontal momentum flux carried by the wind. At the same time, although the particle speed at the surface stays constant, numerical simulations and windtunnel measurements find that the particle speed does increase with shear velocity above the surface. This means that the mass flux higher up in the saltation layer increases relative to that in lower layers, producing a slight increase in the saltation layer height with shear velocity. The extraction of wind momentum by saltating particles produces a steady state wind profile that accelerates saltating particles to a saltate speed that, on average, re-sultsinasingleparticleleavingthesoilbedforeach particle impacting it.

Owen research find that, when the surface shear stress was falls below the impact threshold, fewer saltate particles are entrained by wind. This in turn reduces the transfer of momentum from the fluid to impact particles, there by increasing the surface shearstress-back to its threshold value. Conversely, when the surface shear stress exceeds the threshold value, more saltating particles are entrained, again restoring the surface shear stress to its critical value. The ex-periments of indicate that particles with a larger crosssectional area have a correspondingly higher change of being splashed by a saltating particle [42]. A number of saltates particle have short lifetimes because their high inertia causes them to attain lower speeds when splashed, leading them to quickly settle back to the dust surface [43]. As actually, the wind not directly lifted dust particles that is their interpar-ticle cohesive forces are large compared to aerodynamic forces. Instead, these dust particles mainly collide with each other under wind erosion $[44,45]$. When the dust storm coming, wind accelerated lifted particles and the resulting im-pacts on the dust bed can eject, orsplash, new erosion particles into the fluid stream. This process produces an exponential increase in the particle concentration [46], which leads to increasing drag on the wind, thereby retarding the wind speed in the ero-sion layer [47]. It is this slowing of the wind that acts as a negative feedback by reducing particle speeds, which ultimately limits the number of impacting particles [48].

Dust flux are predominantly emitted by the saltates of erosioning particles on the near surface $[44,45]$. Several studies have also argued that mid-air collisions between can affect particle trajectories and the mass flux at large shear velocities [49,50,51,52]. wind erosion colliding with another it during a single hop is on the order of $10 \sim 50 \%$, and increases with wind speed [52]. That is, even at large impact speeds not all saltating particles rebound from the surface, because some will diginto the particle bed [53]. Moreover, recent meas-urements by indicate that the restitution coefficient is a de-clining function of the saltator impact speed[54].Numerical simulations [39,36, 55,56], labor-atory experiments [57] and theory [43] indicate that the number of splashed particles (N) scales with the im-pacting momentum. The experiments of indicate that the fraction $\alpha$ of the average im-pacting momentum spent on splashing surface particles is of the order of $15 \%$ for a bed of loosesand particles[42,45,43].Most splashed particles therefore move in low-energy reptation trajectories and quickly settle back to the soil bed. However, some splashed particles do gain enough momentum from the wind to participate in saltation and splash up more particles. This mul-tiplication process produces a rapid increase in the particle concentration upon initiation of saltation. the distribution of splashed speeds at a given vejfollows either an exponential or a lognormal distribution $[58,59]$ for a compilation. 
Sand transport has been measured by a lot of instruments developed mainly to determine rates of transport and samples of the transported material. Accurately measuring these processes has been an ongoing challenge since the first known discrete measur ments were made by Bagnold. In general, impact sensors suffer from poor sensitivity to small sand grains [60] and in the case of the Safire, poor interinstrument repeatability [61]. Over the past decade, though the instruments used vary in design and com-plexity but can be split into two categories: integrating and real-time electronic instru-ments. As shall be in this paper, there have been incremental improvements in this latter category of devices that have been motivated, in part, by the observation that sedi-ment transport occurs on spatial scales smaller than 5c $\mathrm{m}$ and temporal scales less than $1 \mathrm{~s}$. Initial designs were improved by increasing the efficiency through taking account of the aerodynamics associated with blocking a portion of the flow [13]. Additional im-provements were made by increasing the temporal resolu-tion through auto- matic weighing systems [27,28]. But, the spatial and temporal resolution of a mass-collecting sediment trap remains insufficient for capturing most small-scale aeolian processes. In addition, because sand traps obstruct the flow to varying degrees, the efficiency of sam-pling saltating grains is variable with height and wind con-ditions [30] but is generally around 80\% [31]. Sand particle size not only differs regionally [62] but also varies signifi-cantly with height $[63,64,65]$. The variations of sand particle size with location and height inevitably influence the sampling efficiency of samplers, leading to errors in the amount of aeolian sand collected. However, in previous experiments this has often been neglected or a fixed sampling efficiency has been applied $[66,67,68,35]$.

To sum up, in the complex environment of the field, the difference in dust horizontal flux and dust collection efficiency is caused by the difference in the type, accuracy, and sam-pling period of the sand samplers, Sand particle size and hinght. Therefore, in the future research, the sand sampling device with high sand collection efficiency and small disturbances to the flow field in complicated fields is an important foundation and prerequisite to accurately estimate the dust flux.

\section{Conclusions}

(1) The cumulative sand collection and number of sand particles impacting sensor of the sand sampler were highly consistent in the complex field environment, with the good linear relationship and $\mathrm{R}^{2}$ value of 0.6053 , reflecting the good performance in sand collection. The sand collection efficiency was about $94.3 \%$ for the sand sampler, indicating that sand sampler could well monitor the movement of sand particles.

(2) In this experiment, sand collector skip turnover increased with the increase of the intensity of dust weather frequency increases, the power function relationship $y=2.115$ $x^{0.9841}, \mathrm{R}^{2}=0.9206$, flip frequency per minute increased from 0.2794 times to 1.3041 times, change is obvious; With the strength of the weather, time to flip the average sediment is shrinking. Sandstorm weather, skip to flip a volume of 3.7160 g, grade I flying sand weather flip a volume of $4.0275 \mathrm{~g}$, the amount of class II flying sand weather turns over a $5.0035 \mathrm{~g}$.

(3) The influence of simultaneously-observed wind speed and temperature on the sand transportation rate within the $5 \mathrm{~cm}$ height indicated that with the increase of wind speed, the sand transportation rate showed the increasing trend, but the variation of sand transportation rate with wind speed was inconsistent in some dust events, during which the soil temperature of $0 \mathrm{~cm}$ at the corresponding time period was significantly large.

Acknowledgments: This work was supported by the "National Natural Science Foundation of China (41905009)" and "Tianshan Youth Talents (Xinjiang)" Plan Project (2019Q037), the Second Tibetan Plateau Scientific Expedition and Research (STEP) program (grant no.2019QZKK010206) and General scientific research project of Xinjiang Meteorological Bureau (MS201907).

\section{References}

[1]UNCCD, Z N L D, 2012. United Nations Convention to Combat Desertification. Bonn. 
[2]Shao Y, 2008. Physics and modelling of wind erosion. Springer Science \& Business Media.

[3]Duce R, Liss P, Merrill J, et al, 1991. The atmospheric input of trace species to the world ocean. Global biogeochemical cycles 5, 193-259.

[4]Lal R, 1994. Soil erosion research methods. CRC Press.

[5]Montgomery D R, 2012. Dirt: the erosion of civilizations. Univ of California press.

[6]Organization WH, 2006. Air quality guidelines: global update 2005: particulate matter, ozone, nitrogen dioxide, and sulfur dioxide. World Health Organization.

[7] Kort J J A, 1988. Benefits of windbreaks to field and forage crops. 22,165-190.

[8] Cleugh H, Hughes D J A Joea, 2002. Impact of shelter on crop microclimates: a synthesis of results from wind tunnel and field experiments. $42,679-701$.

[9] Peri P L, Bloomberg M J A S, 2002. Windbreaks in southern Patagonia, Argentina: A review of research on growth models, windspeed reduction, and effects oncrops. 56, 129-144.

[10] Jasper F Kok, Eric J R Parteli, Timothy I Michaels., 2012. The physics of wind-blown sand and dust. Reports on Progress in Physics, 75 (2012) 106901 (72pp),1-2.

[11] Alemu M J I J E, 2016. Ecological benefits of trees as windbreaks and shelterbelts. 6, 10-13.

[12] Gillette D A, Herbert G, Stockton P H, et al, 1996. Causes of the fetch effect in wind erosion. Earth Surf. Process. Landf. 21, 641-659.

[13] Nickling W G, McKenna Neuman C, 1997. Wind tunnel evaluation of a wedgeshaped aeolian sediment trap. Geomorphology $18,333-345$.

[14] Ono D, Weaver S, Richmond K, 2003. Quantifying Particulate Matter Emissions from Wind Blown Dust using Real-Time Sand Flux Measurements. Pap. Pap. -CEPA, Owens Emiss.

[15] Barchyn T E, Hugenholtz C H, Li B, et al, 2014. From particle counts to flux: wind tunnel testing and calibration of the "Wenglor" aeolian sediment transport sensor. Aeolian Res. 15, 311-318.

[16] Davidson-Arnott, R G D, Bauer B O, 2009. Aeolian sediment transport on a beach: thresholds, intermittency, and high frequency variability. Geomorphology, Contemporary research in aeolian geomorphology6th International Conference on Aeolian Research (ICAR VI) 105, 117-126.

[17] Nholtz C H, Barchyn T E, 2011. Laboratory and field performance of a laser particle counter for measuring aeolian sand transport. J. Geophys. Res. Earth Surf. 116, F01010.

[18] Leonard K C, Cullather R I, 2008. Snowfall measurements in the Amundsen and Bellingshausen Seas, Antarctica. In: Proceedings of the Eastern Snow Conference. pp. 87-98.

[19] Weaver C M, Wiggs G F S, 2011. Field measurements of mean and turbulent airflow over a barchan sand dune. Geomorphology $128,32-41$.

[20] Williams G P, 1964. Some aspects of the eolian saltation load. Sedimentology 9, 89-104.

[21] Arens S M, Van Boxel J H, Abuodha J O Z, 2002. Changes in grain size of sand in transport over a foredune. Earth Surf. Process. Landf. 27, 1163-1175.

[22] Xing M, 2007. The harmonious character in equilibriumaeolian transport onmixed sand bed. Geomorphology 86, $230-242$.

[23] Li Z S, Feng D J, Wu S L, et al, 2008. Grain size and transport characteristics of non-uniform sand in aeolian saltation. Geomorphology 100, 484-493.

[24] Tan L H, Zhang W M, Qu J J, et al, 2014. Variation with height of aeolian mass flux density and grain size distribution over natural surface covered with coarse grains: a mobile wind tunnel study. Aeolian Res. 15, 345-352.

[25] Cheng H, He J J, Zou X Y, et al, 2015. Characteristics of particle size for creeping and saltating sand grains in aeolian transport. Sedimentology 62, 1497-1511.

[26] Yang Y Y, Liu L Y, Li X Y, et al, 2018. Aerodynamic grain-size distribution of blown sand. Sedimentology 66 (2), $590-603$. 
[27] Martin R L, Kok J F, 2019. Size-independent susceptibility to transport in aeolian saltation.J. Geophys. Res. Earth Surf. 124, $1658-1674$.

[28] Namikas S L, 2002. Field evaluation of two traps for high-resolution aeolian transport measurements. J. Coast. Res. 18, 136148.

[29] Haustein K, Washington R, King J, et al, 2015. Testing the performance of state-of-the-art dust emission schemes using DO4Models field data. Geosci. Model Dev. 8, 341-362.

[30] Li Z S, Ni J R, 2003. Sampling efficiency of vertical array aeolian sand traps. Geomorphology 52, $243-252$.

[31] Goossens D, Offer Z, London G, 2000. Wind tunnel and field calibration of five aeolian sand traps. Geomorphology 35, 233252 .

[32] Zhao C M. Analysis of Sand Grain Morphology in Taklimakan Desert. Urumqi: Xinjiang Normal University, 2012 (in Chinese with English abstract).

[33] He Q, Yang X H. Study on wind-induced sand observations in Taklimakan Desert—Preliminary study of test and observation results. Journal of China Desert, 2011, 31 (2): 56-61 (in Chinese with English abstract).

[34] Yang X H, He Q. A field experiment on dust emission by wind erosion in the Taklimakan desert. Act a Meteor, Sinica, 2012, 26 (2):241-249.

[35] Kang Yongde, He Qing. Research on saltation and creeping laws of wind-blown currents based on field observations. Journal of Arid Land Resources and Environment, 2017,31 (5): 119-125 (in Chinese with English abstract).

[36]Anderson R S, Haff P K ,1991. Wind modification and bed response during saltation of sand in air Acta Mech. Suppl.1 21-51

[37]McEwan I K, Willetts B B, 1993. Adaptation of the near-surface wind to the development of sand transport J. Fluid Mech. 252 99-115.

[38]Ungar J E, Haff P K, 1987. Steady-state saltation in air Sedimentology 34 289-99.

[39]Anderson R S, Haff P K, 1988. Simulation of eolian saltation Science 241 820-3.

[40]Anderson R S, Haff P K, 1991. Wind modification and bed response during saltation of sand in air Acta Mech. Suppl.1 21-51. [41]Shao Y, Raupach M R, 1992. The overshoot and equilibration of saltation J. Geophys. Res. 97, $20559-64$.

[42]Rice M A, Willetts B B, McEwan I K, 1995. An experimental study of multiple grain-size ejecta produced by collisions of saltating grains with a flat bed Sedimentology 42, 695-706.

[43]Kok J F, Renno N O, 2009a. A comprehensive numerical model of steady state saltation (COMSALT) J. Geophys. Res.114 D17204.

[44]Gillette D A, 1974. On the production of soil wind erosion having the potential for long range transport J. Rech. Atmos. 8 73444

[45]Shao Y, Raupach M R, Findlater P A, 1993a. Effect of saltation bombardment on the entrainment of dust by wind J. Geophys.Res. 98 12719-26

[46]Dur'an O, Claudin P, Andreotti B, 2011a. On aeolian transport: grain-scale interactions, dynamical mechanisms and scaling laws Aeolian Res. 3 243-70

[47]Bagnold R A, 1936 .The movement of desert sand Proc. R. Soc. Lond. A 157 0594-620 Owen P R 1964 Saltation of uniform grains in air J. Fluid Mech.20 225-42

[48]Owen P R, 1964. Saltation of uniform grains in air J. Fluid Mech.20 225-42

[49]Sorensen M, McEwan I, 1996. On the effect of mid-air collisions on aeolian saltation Sedimentology $4365-76$

[50]Dong Z B, Liu X P, Li F, et al. 2002. Impact-entrainment relationship in a saltating cloud Earth Surf.Process. Landforms 27 641-58

[51]Dong Z B, Huang N, Liu X P, 2005. Simulation of the probability of midair interparticle collisions in an aeolian saltating cloud , J. Geophys. Res. 110 D24113 
[52]Huang N, Zhang Y L, D'Adamo R, 2007. A model of the trajectories and midair collision probabilities of sand particles in a steady state saltation cloud J. Geophys. Res.112 D08206

[53]Rice M A, Willetts B B, McEwan I K, 1996. Observations of collisions of saltating grains with a granular bed from high-speed cine-film Sedimentology 43 21-31

[54]Gordon M, Neuman C M, 2009. A comparison of collisions of saltating grains with loose and consolidated silt surfaces J. Geophys. Res. 114 F04015

[55]Oger L, Ammi M, Valance A, 2005. Discrete Element Method studies of the collision of one rapid sphere on 2D and 3D packings Eur. Phys. J. E 17 467-76

[56]Oger L, Ammi M, Valance A, 2008. Study of the collision of one rapid sphere on 3D packings: experimental and numerical results Comput. Math. Appl. 55 132-48

[57]Werner B T, 1990. A steady-state model of wind-blown sand transport J. Geol. 98 1-17

[58]Mitha S, Tran M Q, Werner B T, et al.1986. The grain-bed impact process in aeolian saltation Acta Mech. 63 267-78

[59]Ho T D, Dupont P, Ould El Moctar A, et al. 2012 Particle velocity distribution in saltation transport Phys. Rev. E 85052301

[60] Van Pelt, R S, Peters P, et al, 2009. Laboratory wind tunnel testing of three commonly used saltation impact sensors. Aeolian Res. 1, 55-62.

[61] Baas, A C W, 2004. Evaluation of saltation flux impact responders (Safires) for measuring instantaneous aeolian sand transport intensity. Geomorph. Aeolian Res.: processes, instrumentation, landforms and palaeoenvironments 59, 99-118.

[62] McKee, E D, 1979. A Study of Global Sand Seas. US Government printing office, Washington.

[63] Dong Z B, Man D Q, Luo W Y, et al, 2010. Horizontal aeolian sediment flux in the Minqin area, a major source of Chinese dust storms. Geomorphology 116, 58-66.

[64] Sharratt B, 2011. Size distribution of windblown sediment emitted from agricultural fields in the Columbia Plateau. Soil Sci. Soc. Am. J. 75, 1054-1060.

[65] Farrell, E J, Sherman D J, et al, 2012. Vertical distribution of grain size for wind blown sand. Aeolian Res. 7, 51-61.

[66] Zhang Z C, Dong Z B, Zhao A G, 2011. The characteristics of aeolian sediment flux profiles in the south-eastern Tengger Desert. Sedimentology 58, 1884-1894.

[67] Pierre C, Bergametti G, Marticorena B, et al, 2014. Modeling wind erosion flux and its seasonality from a cultivated sahelian surface: a case study in Niger. Catena 122, 61-71.

[68] Zhang Z C, Dong Z B, Qian G Q, et al, 2017. An investigation into the pro-cesses and quantity of dust emissions over gravel and sand deserts in north-westernChina. Bound. -Layer Meteorol. 163, 523-535. 